\title{
Extramedullary plasmacytoma in the presence of multiple myeloma: clinical correlates and prognostic relevance
}

This article was published in the following Dove Press journal:

OncoTargets and Therapy

6 November 2012

Number of times this article has been viewed

\author{
Hai-Fei Chen' \\ Tian-Qin Wu' \\ Zheng-Yang $\mathrm{Li}^{\prime}$ \\ Hong-Shi Shen' \\ Jie-Qing Tang' \\ Wei-Jun $\mathrm{Fu}^{2}$ \\ Zhen-Gang Yuan ${ }^{2}$ \\ Jian $\mathrm{Hou}^{2}$ \\ 'Department of Hematology, \\ 100th Hospital of People's Liberation \\ Army, Medical Centre of Hematologic \\ and Oncologic Diseases of Nanjing \\ Military Command, Suzhou, China; \\ ${ }^{2}$ Department of Hematology, Shanghai \\ Changzheng Hospital, The Second \\ Military Medical University, Shanghai, \\ China
}

Objective: We studied the clinical and laboratory features and outcomes of multiple myeloma $(\mathrm{MM})$ with extramedullary plasmocytoma (EP) disease both at diagnosis and during the course of MM.

Patients and methods: Forty-two patients of 467 patients with MM were retrospectively analyzed from both the 100th Hospital of the People's Liberation Army and Shanghai Changzheng Hospitals. The clinical characteristics, laboratory parameters, responses, risk factors, and outcomes were analyzed.

Results: The median age was 53 years with a male/female sex ratio of 34:8. Twenty-six patients had EP disease at the time of diagnosis, and 16 patients developed EP during the course of the disease. We found that the Durie-Salmon stage, serum lactate dehydrogenase level, beta-2microglobulin, complete blood counts, albumin, and the type of immunoglobulin (Ig) were not associated with the development of EP disease. Patients who developed EP during the course of MM had a higher ratio of plasmocytes and premature plasmocytes in the bone marrow with lower C-reactive protein level and earlier stage of International Staging System for Lung Cancer at the diagnosis of MM compared with patients who presented with EP at diagnosis. Once the patients developed EP disease, they frequently showed resistance to chemotherapy. With a median follow-up of 30 months, 19 patients were alive. Log-rank univariate analysis showed that patients with EP who had normal C-reactive protein, higher hemoglobin, lower serum lactate dehydrogenase, and stage I of International Staging System for Lung Cancer had longer survival. However, cyclooxygenase multivariate analysis failed to show statistical significance for any factor.

Conclusions: EP disease is the MM end-phase and is not a rare manifestation of MM with a cumulative incidence of $9 \%$ of MM. The prognosis is very poor once the diagnosis of EP disease is concurrent with MM.

Keywords: diagnosis, extramedullary multiple myeloma, plasmacytoma

\section{Introduction}

Multiple myeloma (MM), known as plasma cell myeloma, is a clonal B-cell malignancy of terminally differentiated plasma cells. There is an evolution of myeloma from a relatively benign to a highly malignant transformed phase similar to low-grade lymphomas, chronic lymphocytic, myelogenous leukemias, and myelodysplastic syndromes. ${ }^{1}$ Before entering into an aggressive phase, the disease mainly resides within the bone marrow; during the latter highly transformed phase, there is a frequent occurrence of extramedullary manifestations. Extramedullary plasmacytomas (EP) have an incidence of $7 \%-17 \%$ in patients at the time of diagnosis and $6 \%-20 \%$
Correspondence: Tian-Qin Wu Department of Hematology, I00th Hospital of People's Liberation Army, Medical Centre of Hematologic and Oncologic Diseases of Nanjing Military Command, Suzhou 215007, China Emailwtq100@vip.163.com 
during the course of the disease. ${ }^{2}$ The sites of predilection for EP are asopharynx, larynx, and upper respiratory tract. ${ }^{3}$ However, the gastrointestinal tract, ${ }^{4,5}$ pleura, ${ }^{6}$ testis, ${ }^{7,8}$ skin,,${ }^{9,10}$ peritoneum, ${ }^{11}$ liver, ${ }^{12}$ endocrine glands, ${ }^{13}$ and lymph nodes ${ }^{14}$ are typically involved in the context of disseminated MM. However, these localizations are not very common. A recent study reported by Fassas et al suggested that a central nervous system (CNS)-localized EP was associated with specific features. ${ }^{15}$ In the present study, we analyzed the characteristics of $42 \mathrm{MM}$ patients with EP manifestations either present at the time of diagnosis or developed during the course of the disease.

\section{Materials and methods}

We retrieved all 467 patients with a diagnosis of MM from the 100th Hospital of the People's Liberation Army and Shanghai Changzheng Hospitals between January 1993 and August 2008. Approximate four-fifths of these patients were primarily diagnosed and followed-up at the hospitals and the remaining patients were referred to our hospitals for intensive therapy. All medical documents were reviewed. Patients with EP at diagnosis or during the course of the disease were collected and analyzed. Here, we defined EP disease by the presence of plasmacytomas in organs besides bones. Patients with solitary plasmacytoma were excluded from participation in the study. We performed the following analyses: physical examination, serum creatinine, complete blood count, calcium, C-reactive protein (CRP), serum lactate dehydrogenase (LDH), beta-2 macroglobulin, albumin levels, urinary protein electrophoresis, and immunofixation. We also used standard bone and chest $\mathrm{X}$-rays, lumbar puncture, abdominal ultrasonography, or a cerebral computed tomography/magnetic resonance imaging scan when indicated.

In this analysis, MM diagnoses were defined according to the criteria of International Myeloma Working Group ${ }^{16}$ and responses to treatments such as complete and partial remissions (CR and $\mathrm{PR}$ ) and progressive disease (PD) status were defined according to the Bladè criteria. ${ }^{17}$

We used the Kaplan-Meier method to count the survival. ${ }^{18}$ Factors associated with overall survival were identified using univariate analysis. All factors identified were entered into a Cox proportional hazards mode ${ }^{19}$ to determine which factors were independently associated with survival.

\section{Results}

Among the 467 patients analyzed, 42 patients were found to meet the definition of EP disease, representing a cumulative incidence of $8.99 \%$. The median age of the group, which included 34 males and eight females at MM diagnosis, was 52.8 years of age (range: $28-76$ years). Seven patients had IgA monoclonal component while 18 had an IgG monoclonal component. Additionally, four patients had $\operatorname{IgD}$ and three patients had nonsecretory, while ten had light chain. All patients except two had Durie-Salmon stage III disease at diagnosis. Moreover, four patients had impaired renal function and no patient had hypercalcemia. Nineteen patients were still alive with a median survival time of 28 months after a median follow-up of 30 months from the diagnosis of MM (Figure 1). Log-rank univariate analysis showed that patients with EP who had lower CRP $(\leq 10 \mathrm{mg} / \mathrm{L})$, higher hemoglobin ( $\geq 110 \mathrm{~g} / \mathrm{L})$, lower serum LDH ( $\leq 270 \mathrm{U} / \mathrm{L})$, and stage I according to the International Staging System for Lung Cancer had a longer period of survival. However, cyclooxygenase multivariate analysis failed to show statistical significance for any factor.

Twenty-six patients presented with EP at diagnosis. Soft tissues were the most common site involved in plasmacytoma followed by pleura/peritonea and lymph nodes. Five patients presented with CNS involvement (Table 1). Ten patients had involvement of two to four sites. Thirteen patients had a single site involvement and two patients had more than five. A plasmoblastic cell component was present in ten patients. The laboratory characteristics at the diagnosis of MM and the time and dose that thalidomide was used during the follow-up are shown in Table 2. CRP level was higher in patients with EP disease at the diagnosis of MM than in patients who developed EP during the course of the disease. The ratio of bone marrow total plasmocytes and premature plasmocytes (plasmoblast plus immature plasmocyte) in patients with EP at the diagnosis

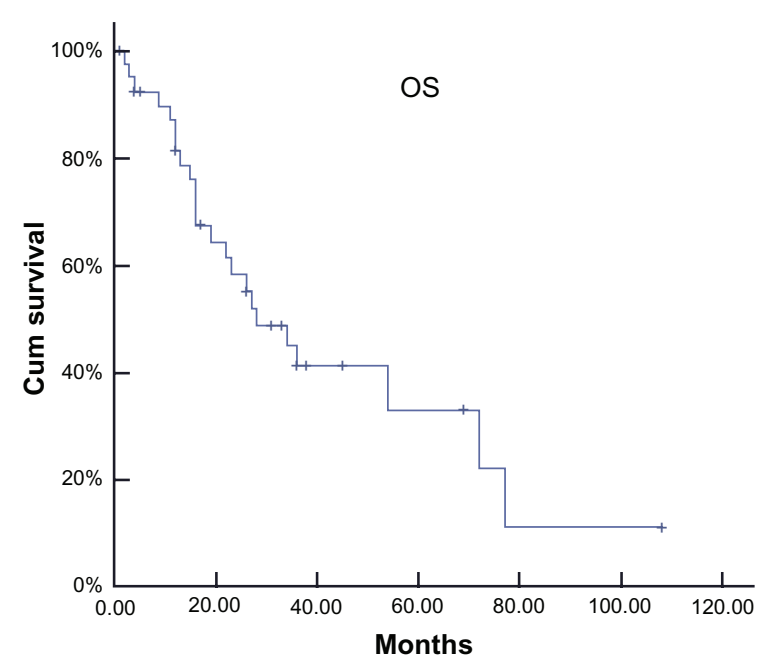

Figure I Survival of the whole group from the diagnosis of myeloma. 
Table I Sites of EP involvement

\begin{tabular}{lll}
\hline EP & $\begin{array}{l}\text { At diagnosis } \\
(\mathbf{n = 2 6 )}\end{array}$ & $\begin{array}{l}\text { In the course of the disease } \\
(\mathbf{n}=\mathbf{1 6})\end{array}$ \\
\hline Soft tissues & 13 & 9 \\
Pleura/peritonea & 9 & 4 \\
Lymph nodes & 5 & 3 \\
CNS & 5 & 5 \\
Lungs & 2 & 4 \\
Spleen enlargement & 3 & 2 \\
Liver & 2 & 1 \\
Breast & 1 & 1 \\
Trachea & 1 & \\
Tongue & 1 & \\
Ocular adnexal & & 1 \\
\hline
\end{tabular}

Abbreviations: CNS, central nervous system; EP, extramedullary plasmocytoma.

of MM was lower than in patients who developed EP (Table 2). All patients received an alkylating agent and dexamethasonebased chemotherapy. Moreover, four patients received surgical intervention and four patients received radiotherapy. No patients received autologous stem cell transplantation. In addition, twelve patents received thalidomide plus alkylating agent and dexamethasone-based therapy. None responded to thalidomide alone. The total response was very low. Only one patient response was $\mathrm{CR}$, but the duration was less than 3 months, after which the patient relapsed. Four patients did not respond to treatment and had progressive disease (PD) during the follow-up period. After a median follow-up of 17 months (range: $1-54$ months), the median survival time was 16 months, with three patients alive in PR and eight patients alive in stable disease or PD (Figure 2).

In contrast, 16 patients developed EP during the course of the disease. First-line chemotherapy for MM before the diagnosis of EP disease was MP (melphalan: $6 \mathrm{mg} / \mathrm{m}^{2} /$ day; prednisone: $40 \mathrm{mg} / \mathrm{m}^{2} /$ day; days: $\left.1-4\right)(\mathrm{n}=2)$; M2 (vincristine: $2 \mathrm{mg} /$ day; cyclophosphamide: $400 \mathrm{mg} / \mathrm{m}^{2} /$ day; 1,3-bis $(2-$ chloroethyl)-1-nitrosourea: $20 \mathrm{mg} / \mathrm{m}^{2} /$ day; days: 1 ; melphalan: $6 \mathrm{mg} / \mathrm{m}^{2} /$ day, days: $1-4$; prednisone: $40 \mathrm{mg} / \mathrm{m}^{2} / \mathrm{d}$, days: $1-14$ ) $(\mathrm{n}=4)$; VAD (vincristine: $0.4 \mathrm{mg} / \mathrm{m}^{2} /$ day; adriamycin: $9 \mathrm{mg} / \mathrm{m}^{2} /$ day; dexamethasone: $40 \mathrm{mg} /$ day; days: $\left.1-4\right)(\mathrm{n}=8)$ or VAD + high-dose therapy (HDT; $\mathrm{n}=1)$. Apart from the combined chemotherapy, two patients received surgical intervention and five patients received radiotherapy. In addition, ten patients were administered thalidomide and one patient received proteasome inhibitor bortezomib. The patients who received bortezomib developed CNS plasmocytoma 2 months later. In all patients, only one patient was in complete remission (CR) and two patients had a very good partial response and 8 patients had a partial response while five patients had PD. In this subgroup, the mean interval from diagnosis of MM to diagnosis of EP disease was 24.4 months (range: 8.5-101.1 months). However, once EP developed during the course of disease, no patients responded to intervention, even to the bortezomib or radiotherapy. The accumulative dose and use time of thalidomide in patients during the course of disease were higher in patients with EP disease at the time of diagnosis (Table 2). In this group, soft tissues $(n=9)$, CNS $(n=5)$, pleura/peritonea $(n=4)$, and lung $(n=4)$ were the first four involvements (Table 2). Multiple site involvement was found in seven patients and single organ involvement was found in eight patients. At the time of diagnosis of EP disease, all except three patients had evidence of systemic disease. After a median follow-up of 72 months (range: 17-108 months) from diagnosis, eight patients are still alive (partial response, $n=4 ; P D, n=4$ ), with an estimated median survival time of 72 months after diagnosis of MM (Figure 1). For further analysis, the estimated survival time is 13 months from the diagnosis of EP disease in this subgroup (Figure 3).

\section{Discussion}

We report a group of 42 patients with EP disease in MM over a period of 13 years for an overall crude prevalence of approximately $9 \%$. The soft tissues, pleura/peritonea, and CNS were the sites most frequently involved in EP disease. CNS involvement was similar to both EP at diagnosis and EP in the course of the disease. In a study of 25 cases with CNS involvement in MM, plasmoblastic morphology, poor cytogenetic abnormalities, high tumor burden, and high LDH levels were found to be associated with CNS MM. ${ }^{20}$ Though there were ten patients with CNS involvement in our series, no factors were found to be associated with CNS MM. In another study, Garcia-Sanz et al reported that EP disease was frequent in plasma cell leukemia and in patients with type $\mathrm{D}$ heavy chain. In a study of 26 patients with primary plasma cell leukemia, a higher EP disease incidence was observed compared to patients with MM. ${ }^{21}$ Similar findings have also been reported by Dimopoulos et al. ${ }^{22}$ Twenty-six out of 27 patients with plasma cell leukemia had EP sites at the time of diagnosis. ${ }^{22}$ Jancelewicz et $\mathrm{al}^{23}$ found that more than $50 \%$ of patients with IgD MM had EP disease at the time of diagnosis. However, Damaj et $\mathrm{al}^{24}$ reported that there were no association between the laboratory characteristics of MM at diagnosis and the incidence of EP disease. Our result is similar to that of Damaj's study. Nevertheless, the plasmocyte labeling index, cytogenetic studies, and immunophenotyping were not performed systematically in this retrospective study, and the relationship between these parameters and the ability 
Table 2 Patient characteristics at the time of MM diagnosis and parameters during thalidomide treatment

\begin{tabular}{|c|c|c|c|}
\hline & $\begin{array}{l}\text { EP at diagnosis } \\
(n=26)\end{array}$ & $\begin{array}{l}\text { EP in the course of disease } \\
(n=16)\end{array}$ & $P$ value \\
\hline $\operatorname{Sex}(M / F)$ & $22 / 4$ & $12 / 4$ & \\
\hline Age (mean $\pm S D)$ & $53.24 \pm 2.83$ & $52.06 \pm 3.02$ & NS \\
\hline \multicolumn{4}{|l|}{ Durie-Salmon stage } \\
\hline \multicolumn{4}{|l|}{$\| \mathrm{A}$} \\
\hline IIIA & 22 & 2 & 0.077 \\
\hline IIIB & 4 & 14 & \\
\hline Ig type & & & NS \\
\hline $\lg G$ & 12 & 6 & \\
\hline $\lg A$ & 3 & 4 & \\
\hline $\lg D$ & 3 & I & \\
\hline Light chain $(\kappa / \lambda)$ & $4 / 3$ & $1 / 2$ & \\
\hline Nonsecretory & I & 2 & \\
\hline $\mathrm{Hb}(\mathrm{g} / \mathrm{L})($ mean $\pm \mathrm{SD})$ & $93.20 \pm 5.08$ & $104.13 \pm 8.07$ & NS \\
\hline WBC $\left(10^{9} / L\right)($ mean $\pm S D)$ & $5.85 \pm 0.55$ & $4.64 \pm 0.47$ & NS \\
\hline Platelets $\left(10^{9} / \mathrm{L}\right)$ & $252.96 \pm 54.66$ & $165.93 \pm 19.88$ & NS \\
\hline Serum creatinine $(\mu \mathrm{mol} / \mathrm{L})($ mean $\pm \mathrm{SD})$ & $100.46 \pm 12.78$ & $113.40 \pm 23.88$ & NS \\
\hline Serum calcium $(\mathrm{mmol} / \mathrm{L})($ mean $\pm \mathrm{SD})$ & $2.421 \pm 0.077$ & $2.36 \pm 0.029$ & NS \\
\hline$\beta 2-M G(g / L)($ mean $\pm S D)$ & $5.08 \pm 0.83$ & $5.14 \pm 1.37$ & NS \\
\hline $\mathrm{CRP}(\mathrm{mg} / \mathrm{L})($ mean $\pm \mathrm{SD})$ & $30.42 \pm 11.48$ & $7.19 \pm 1.23$ & 0.056 \\
\hline $\mathrm{LDH}(\mathrm{u} / \mathrm{L})($ mean $\pm \mathrm{SD})$ & $252.96 \pm 54.66$ & $188.53 \pm 19.08$ & NS \\
\hline Albumin $(g / L)$ & $33.16 \pm 1.44$ & $37.80 \pm 1.77$ & NS \\
\hline BM: total plasmocytes $(\%)($ mean \pm SD) & $28.14 \pm 5.06$ & $44.57 \pm 4.63$ & 0.022 \\
\hline BM: premature plasmocytes $(\%)($ mean \pm SD) & $22.86 \pm 4.55$ & $36.83 \pm 4.11$ & 0.029 \\
\hline PB: plasmocyte (n) & 2 & I & \\
\hline ISS & & & 0.027 \\
\hline I stage & 6 & 8 & \\
\hline Il stage & 15 & 3 & \\
\hline III stage & 5 & 5 & \\
\hline Thal. (n) & 12 & 10 & NS \\
\hline Thal. accumulative used time (month) (mean \pm SD) & $4.07 \pm 0.75$ & $12.2 \pm 4.65$ & 0.073 \\
\hline Thal. accumulative dose $(\mathrm{g})($ mean $\pm \mathrm{SD})$ & $28.64 \pm 6.75$ & $68.25 \pm 31.75$ & NS \\
\hline
\end{tabular}

Abbreviations: BM, bone marrow; CRP, C-reactive protein; EP, extramedullary plasmocytoma; Hb, hemoglobin; lg, immunoglobulin; LDH, lactate dehydrogenase (normal level < 245 IU/L); NS, nonsignificant; PB, peripheral blood; SD, standard deviation; Thal., thalidomide; WBC, white blood cells.

to develop EP could, therefore, not be addressed. However, patients who developed EP during the course of disease had a significantly higher ratio of bone marrow plasmocytes and premature plasmocytes than that of patients at the time of diagnosis of MM. In addition, EP disease occurred more commonly in males than in females in our study, and whether the cause is associated with race remains unknown.

This is the largest study of patients with EP from the Chinese population and in Asia. The published data showed that the overall survival of patients with EP disease is generally short. ${ }^{20,24}$ Compared to the treatment intervention in EP disease in Europe/America, we found only one patient who received HDT followed by autologous peripheral blood stem cell transplants (APBSCT) in our series, while most patients in developed countries received HDT followed by APBSCT. However, the median overall survival of our patients was 28 months and was much longer than that of the European group. The result indicates that the role of HDT followed by APBSCT is limited in EP disease in Chinese people. This may be due to differences in race, diet composition, and environment. Overall survival in our group was longer than in other groups due to the following: (i) IgG type MM in our group was the majority and (ii) patient mean age (53 years of age) was younger in our series than that of others. Nevertheless, the overall survival in the patients with EP at the time of diagnosis of MM in our series was similar to that of other groups. Clearly, the longer overall survival is due to those patients who developed EP disease during the course of MM. It is not clear why the patients had a long overall survival in this subgroup. We observed that the myeloma evolved from a relatively benign process to a highly malignant transformed phase ("malignant myeloma"). In the indolent stage or overt phase of myeloma, the myeloma cells are completely dependent 


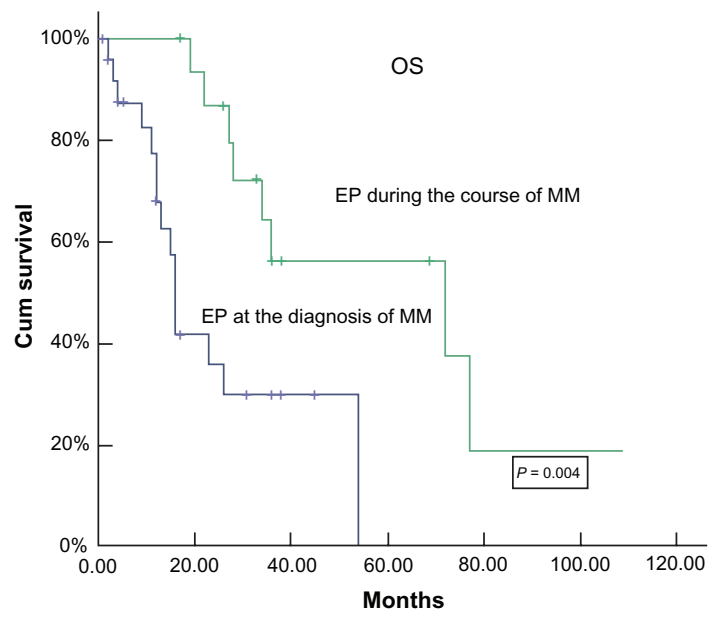

Figure 2 Survival of two groups from the diagnosis of myeloma.

on the bone marrow stroma for survival and growth and are chemosensitive. Therefore, patients who received chemotherapy such as thalidomide or combined conventional chemotherapy delayed the development of EP and had a long duration of response. However, in the aggressive terminal phase, myeloma cells become independent of the bone marrow stroma. The myeloma has become essentially resistant to chemotherapy and survival times are poor, even with high-dose chemotherapy and APBSCT. Notably, two patients with CNS involvement received proteasome inhibitor bortezomib therapy combination therapy with dexamethasone or with the cytotoxic agents in our series. The efficacy in our patients was very limited, in accordance with the previous data from Ali et al. ${ }^{25}$ Although bortezomib has been reported to induce responses in approximately one-third of patients with refractory or relapsed $\mathrm{MM},{ }^{26}$ bortezomib shows extensive tissue penetration; however, the data from

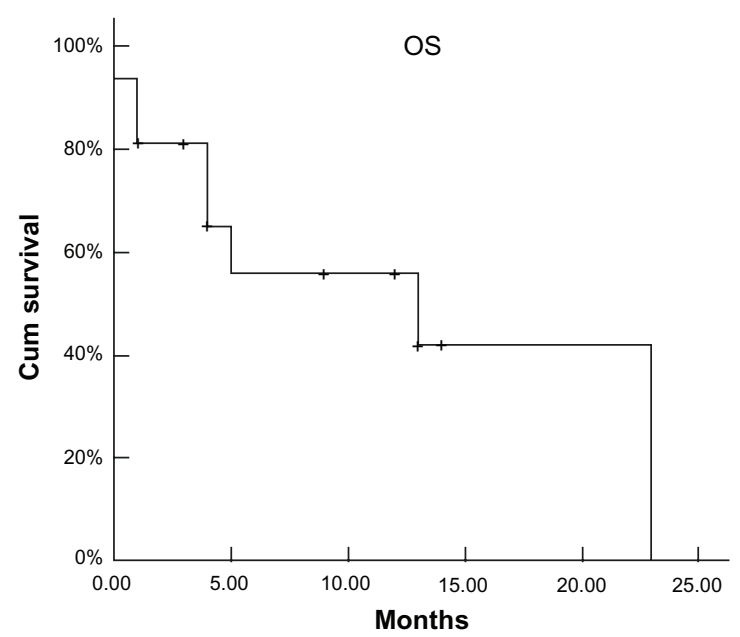

Figure 3 Survival of myeloma patients from the development of extramedullary plasmacytoma. studies conducted in nonhuman primates have indicated that bortezomib does not penetrate into the CNS or into various regions of the eye. ${ }^{27}$

In conclusion, myeloma with EP is not a rare disease. Once the EP disease is developed, the response to conventional chemotherapy, thalidomide, bortezomib, HDT, and/or radiotherapy is poor and newer treatments are urgently needed.

\section{Disclosure}

The authors declare that there were no conflicts of interest in this work.

\section{References}

1. Hallek M, Bergsagel PL, Anderson KC. Multiple myeloma: increasing evidence for a multistep transformation process. Blood. 1998;91(1): 3-21.

2. Oriol A. Multiple myeloma with extramedullary disease. Adv Ther. 2011;28 Suppl 7:1-6.

3. Uppal HS, Harrison P. Extramedullary plasmacytoma of the larynx presenting with upper airway obstruction in a patient with long-standing IgD myeloma. J Laryngol Otol. 2001;115(9):745-746.

4. Chetty R, Bramdev A, Reddy AD. Primary extramedullary plasmacytoma of the esophagus. Ann Diagn Pathol. 2003;7(3):174-179.

5. Chim CS, Wong WM, Nicholls J, Chung LP, Liang R. Extramedullary sites of involvement in hematologic malignancies: case 3 . Hemorrhagic gastric plasmacytoma as the primary presentation in multiple myeloma. J Clin Oncol. 2002;20(1):344-347.

6. Kintzer JS Jr, Rosenow EC 3rd, Kyle RA. Thoracic and pulmonary abnormalities in multiple myeloma. A review of 958 cases. Arch Intern Med. 1978;138(5):727-730.

7. Fernandez LA, Couban S, Sy R, Miller R. An unusual presentation of extramedullary plasmacytoma occurring sequentially in the testis, subcutaneous tissue, and heart. Am J Hematol. 2001;67(3):194-196.

8. Giuliani N, Caramatti C, Roti G, et al. Hematologic malignancies with extramedullary spread of disease. Case 1. Multiple myeloma with extramedullary involvement of the pleura and testes. J Clin Oncol. 2003;21(9):1887-1888.

9. Green T, Grant J, Pye R, Marcus R. Multiple primary cutaneous plasmacytomas. Arch Dermatol. 1992;128(7):962-965.

10. Rosenblum MD, Bredeson CN, Chang CC, Rizzo JD. Subcutaneous plasmacytomas with tropism to sites of previous trauma in a multiple myeloma patient treated with an autologous bone marrow transplant. Am J Hematol. 2003;72(4):274-277.

11. Alegre A, Martinez-Chamorro C, Fernandez-Ranada JM. Massive myelomatous ascites responsive to VAD chemotherapy and autologous stem cell transplantation. Bone Marrow Transplant. 1999;24(3): 343-344.

12. Petrucci MT, Tirindelli MC, De Muro M, Martini V, Levi A, Mandelli F. Extramedullary liver plasmacytoma a rare presentation. Leuk Lymphoma. 2003;44(6):1075-1076.

13. Fujikata S, Tanji N, Aoki K, Ohoka H, Hojo N, Yokoyama M. Extramedullary plasmacytoma arising from an adrenal gland. Urology. 2002;60(3):514.

14. Menke DM, Horny HP, Griesser H, et al. Primary lymph node plasmacytomas (plasmacytic lymphomas). Am JClin Pathol. 2001;115(1): $119-126$.

15. Fassas AB, Muwalla F, Berryman T, et al. Myeloma of the central nervous system: association with high-risk chromosomal abnormalities, plasmablastic morphology and extramedullary manifestations. $\mathrm{Br} J$ Haematol. 2002;117(1):103-108. 
16. International Myeloma Working Group. Criteria for the classification of monoclonal gammopathies, multiple myeloma and related disorders: a report of the International Myeloma Working Group. Br J Haematol. 2003;121(5):749-757.

17. Bladé J, Samson D, Reece D, et al. Criteria for evaluating disease response and progression in patients with multiple myeloma treated by high-dose therapy and haemopoietic stem cell transplantation. Myeloma Subcommittee of the EBMT. European Group for Blood and Marrow Transplant. Br J Haematol. 1998;102(5):1115-1123.

18. Dinse GE, Lagakos SW. Nonparametric estimation of lifetime and disease onset distributions from incomplete observations. Biometrics. 1982;38(4):921-932.

19. Cox DR. Regression models and life-tables. JRoy Stat Soc B. 1972;34(2): $187-220$.

20. Fassas ABT, Ward S, Muwalla F, et al. Myeloma of the central nervous system: Strong association with unfavorable chromosomal abnormalities and other high-risk disease features. Leuk Lymphoma. 2004;45(2):291-300.

21. Garcia-Sanz R, Orfao A, Gonzalez M, et al. Primary plasma cell leukemia: clinical, immunophenotypic, DNA ploidy, and cytogenetic characteristics. Blood. 1999;93(3):1032-1037.
22. Dimopoulos MA, Palumbo A, Delasalle KB, Alexanian R. Primary plasma-cell leukaemia. Br J Haematol. 1994;88(4):754-759.

23. Jancelewicz Z, Takatsuki K, Sugai S, Pruzanski W. IgD multiple myeloma. Review of 133 cases. Arch Intern Med. 1975;135(1):87-93.

24. Damaj G, Mohty M, Vey N, et al. Features of extramedullary and extraosseous multiple myeloma: a report of 19 patients from a single center. Eur J Haematol. 2004;73(6):402-406.

25. Ali R, Ozkalemkas F, Ozkan A, et al. Bortezomib and extramedullary disease in multiple myeloma: the shine and dark side of the moon. Leuk Res. 2007;31(8):1153-1155.

26. Kane RC, Bross PF, Farrell AT, Pazdur R. Velcade: US FDA approval for the treatment of multiple myeloma progressing on prior therapy. Oncologist. 2003;8(6):508-513

27. Bold R. "Development of the proteasome inhibitor Velcade (Bortezomib)" by Julian Adams, PhD, and Michael Kauffman, MD, PhD. Cancer Invest. 2004;22(2):304-311.
OncoTargets and Therapy

\section{Publish your work in this journal}

OncoTargets and Therapy is an international, peer-reviewed, open access journal focusing on the pathological basis of all cancers, potential targets for therapy and treatment protocols employed to improve the management of cancer patients. The journal also focuses on the impact of management programs and new therapeutic agents and protocols on

\section{Dovepress}

patient perspectives such as quality of life, adherence and satisfaction. The manuscript management system is completely online and includes a very quick and fair peer-review system, which is all easy to use. Visit http://www.dovepress.com/testimonials.php to read real quotes from published authors. 